\title{
PYODERMA GANGRENOSUM OF THE ORBIT
}

\author{
W. D. NEWMAN and H. J. FRANK \\ Bournemouth
}

\begin{abstract}
SUMMARY
Pyoderma gangrenosum is an uncommon chronic ulcerative condition, the aetiology of which is poorly understood. Ophthalmic involvement is rare. The case presented in this paper involves destruction of the orbital contents with subsequent perforation of the eye despite conventional therapy. Evisceration was performed with the patient being subjected to hyperbaric oxygen therapy pre- and post-operatively, with resultant cessation of the disease process.
\end{abstract}

Pyoderma gangrenosum is an uncommon chronic inflammatory, ulcerative skin disorder which may occur at any age and has a female preponderance. A strong association exists with inflammatory bowel disease and the arthritides, $50-80 \%$ of cases being associated with an underlying medical condition (Table I). ${ }^{1-4}$ The lesions have a predilection for the abdomen and legs, although they can occur at any site. ${ }^{3,5,6}$ Ophthalmic pyoderma gangrenosum is extremely rare and, of the 5 reported cases, only 1 involved the orbit.

Brusting et al. published the classical description of pyoderma gangrenosum in 1930: 'The borders of the ulcers are well-defined because of their striking blue color which clearly outlined the lesion as it extended peripherally in rough, serpiginous configuration. The blue zone consisted of an oedematous, boggy strip from 5 to $8 \mathrm{~mm}$ wide in which there had been extensive undermining and necrosis of the subcutaneous tissue, the epidermis remaining as a thin, gray, translucent film extending over the crater of the lesion in a ragged, irregular fashion'?

The lesions often start at the site of minor trauma or surgical wounds $\mathrm{s}^{3,4}$ as a small erythematous papule which may look like a folliculitis. These progress to tender sterile pustules, the centres of which necrose and become covered in pus with ragged undermined violaceous edges. ${ }^{1,2}$ These lesions are noted for their exquisite painfulness. ${ }^{3}$

The diagnosis, after the exclusion of other disease, is

Correspondence to: Miss H. J. Frank, Consultant Ophthalmic Surgeon, Royal Victoria Hospital, Westbourne, Bournemouth BH4 9DG, UK. essentially clinical. Biopsy of tissue from the lesions may show an intense lymphocytic infiltrate with fibrinoid necrosis peripherally and an increasing proportion of polymorphs towards the centre. Biopsy, though not diagnostic, is helpful when considering the exclusion of other disorders.

While the aetiology is not known, defects in the immune system play a key role. Abnormalities of cellular immunity have been shown in some patients along with reduced production of macrophage inhibitory factor ${ }^{8}$ and disorder of chemotaxis and phagocytosis by polymorphs and monocytes. $T$ cells subgroup abnormalities have been demonstrated in these patients and may be related to the

Table I. Diseases associated with pyoderma gangrenosum ${ }^{3}$

Common associations

Inflammatory bowel disease

Chronic ulcerative colitis (CUC)

Regional enteritis, granulomatous colitis (Crohn's disease) Arthritis

Seronegative with IBD

Seronegative without IBD

Rheumatoid arthritis

Spondylitis

Osteoarthritis

Haematological diseases

Myelocytic leukaemias

Hairy cell leukaemia

Myelofibrosis, agnogenic myeloid metaplasia

Monoclonal gammopathy (IgA)

Rarely reported associations

Chronic active hepatitis

Myeloma

Polycythaemia rubra vera

Paroxysmal nocturnal haemoglobinuria

Takayasu's arteritis

Primary biliary cirrhosis

Systemic lupus erythematosus

Wegener's granulomatosis

Hidradenitis suppurativa

Acne conglobata

Malignancy

Thyroid disease

Pulmonary disease

Sarcoidosis

Diabetes mellitus

Other pustular dermatoses 

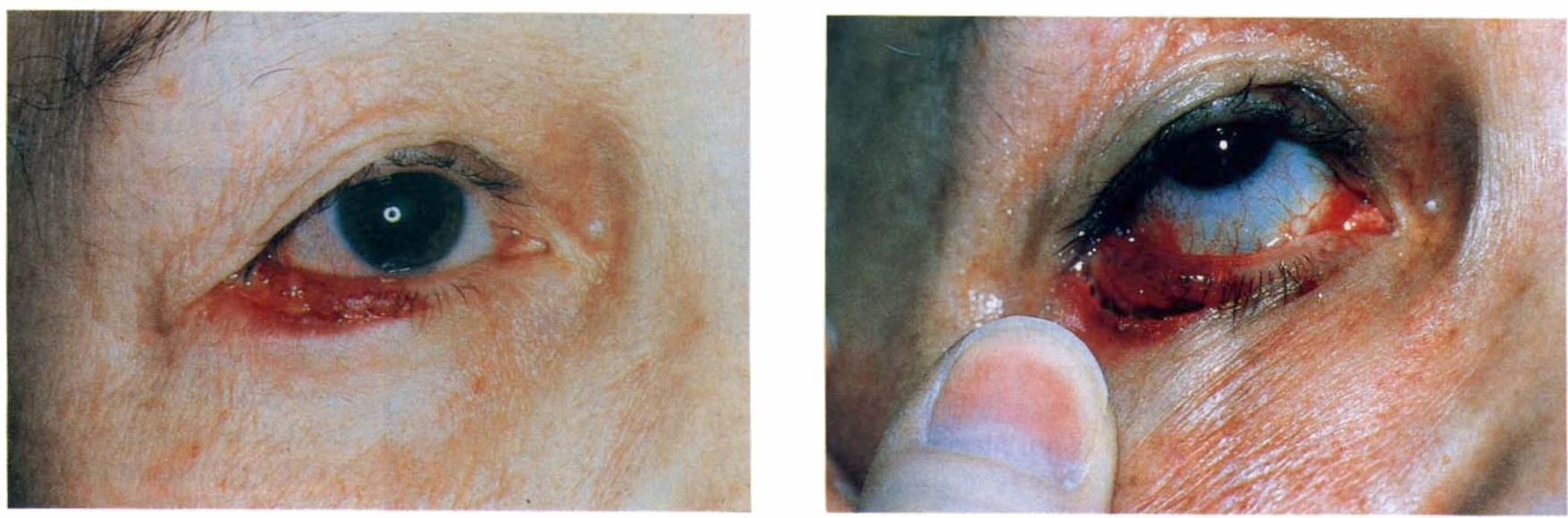

Fig. 1. Photographs, August 1988.
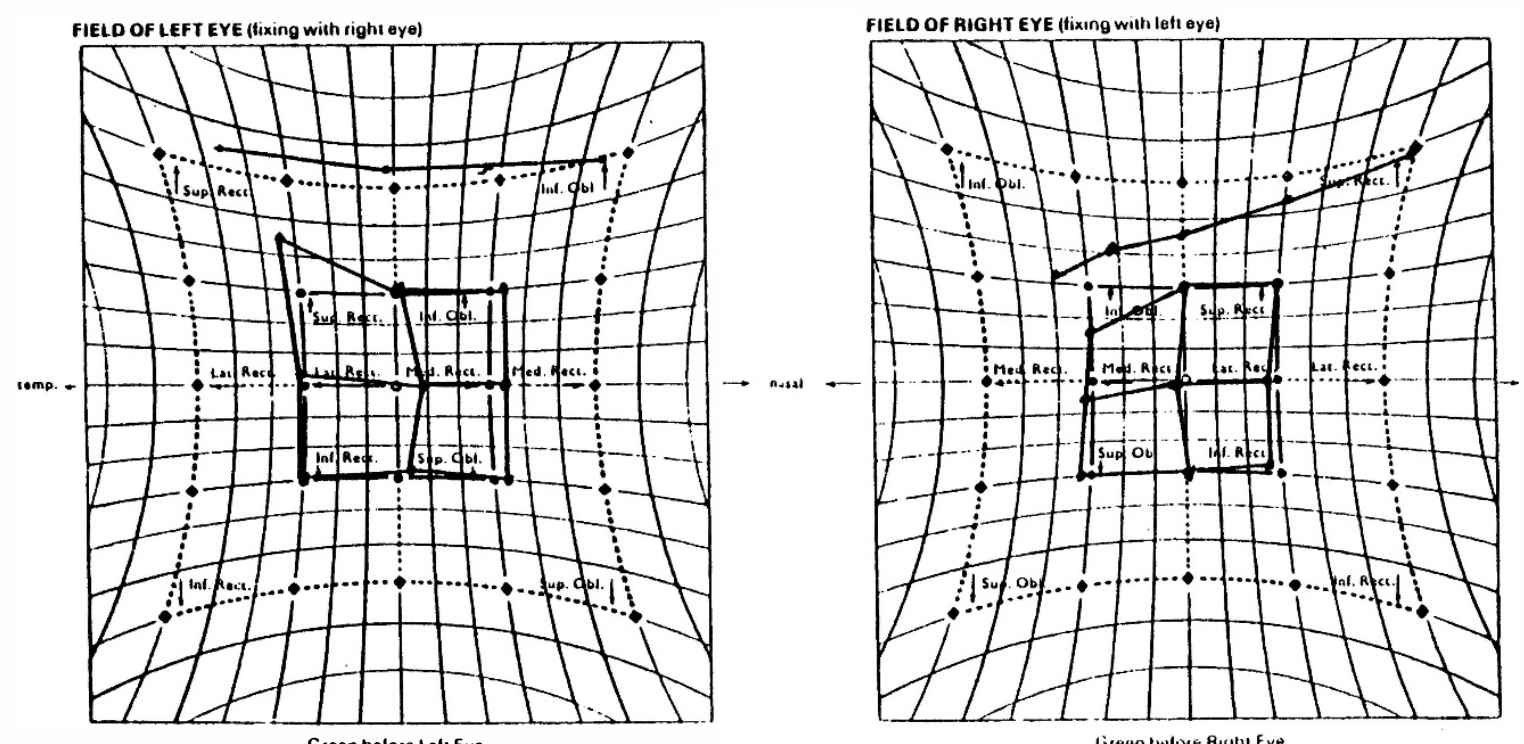

DIAGNOSIS

Green belore Left Eye

Fig. 2. Hess chart, November 1989.
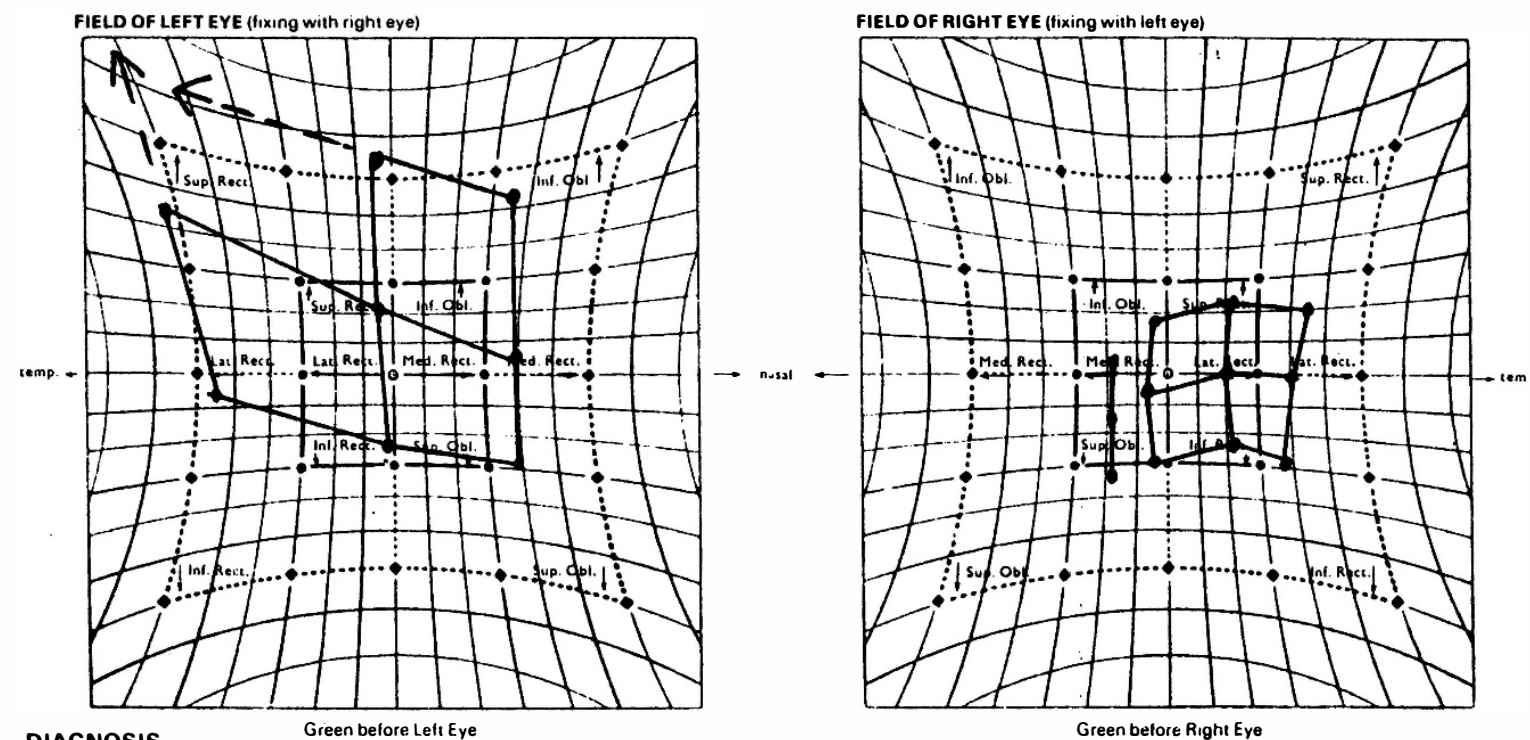

Fig. 3. Hess chart, May 1990. 


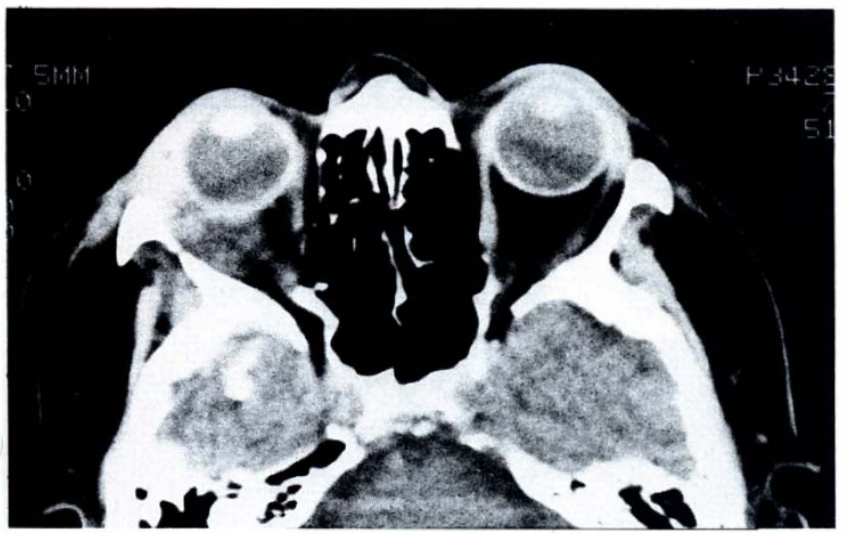

Fig. 4. CT scan, June 1990. (NB: The right side of the patient is on the left side of the scan.)

basic pathological defect as $T$ cells are involved in the regulation of both macrophage inhibitory factor and neutrophil function. It is not known whether the ulceration occurs passively due to this immune dysfunction or, as others who have not found the abnormalities described above have suggested, the lesions are the result of an inappropriate inflammatory response against some factor in the skin. ${ }^{6}$ The role of infection is secondary to defects such as impaired intracellular killing by hypoxic leucocytes, rather than being the primary pathological process as originally postulated. ${ }^{7}$ As with the analysis of histological specimens, there is at present no single pattern of immunological or bacteriological dysfunction sufficient to characterise the disease. . $^{1,3,9}$

Healing only occurs with the cessation of the inflammatory process accompanied by re-epithelialisation from the edges to the centre of the ulcer, the cicatrix being likened to cigarette paper, remaining tender and vulnerable for some time. ${ }^{3}$

\section{CASE REPORT}

In August 1988 a 67-year-old woman attended the accident department with a lesion on her right lower lid. She had been diabetic for 10 years, controlled on glibenclamide and metformin for the previous 5 years. Her lower

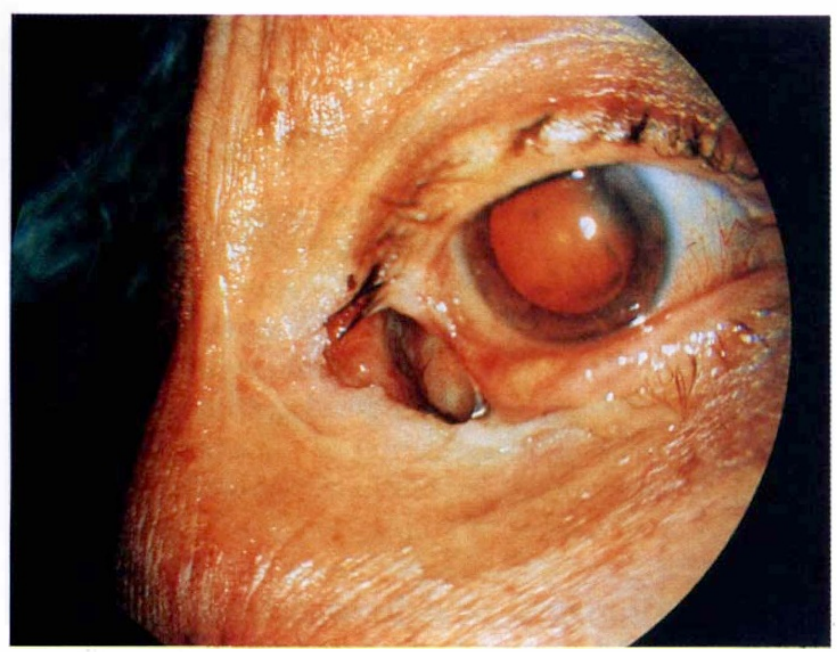

Fig. 5. Photograph, March 1991. abdominal wall had become ulcerated over the 2 years prior to presentation, and she was receiving treatment from the dermatologist who had diagnosed this as pyoderma gangrenosum.

The patient came to casualty with what she thought was a stye on her right lower lid. The lesion had been present since June and had slowly enlarged, burst, and discharged pus. It was very painful and failed to heal despite treatment with systemic and local antibiotics. Culture of the discharge did not identify any pathogen.

In October 1988 the lesion was considered to be typical of pyoderma gangrenosum as there was a linear ulcer running parallel to the lid margin with violaceous edges. Gentle traction on the lower lid caused it to fall open to a depth of at least $1 \mathrm{~cm}$ as if it had been dissected to separate the internal and external lamellae of the lid (Fig. 1). The patient was treated with oral and intralesional steroids and her diabetic control was improved with a change to insulin. Over a 3-month period the ulcer almost healed and the oral prednisolone was reduced from $40 \mathrm{mg}$ to $5 \mathrm{mg}$.

In June 1989 the eyelid ulcer relapsed, a deep fissure again being visible. The oral steroids were increased but there was no clinical improvement over a 2-month period and a trial of oral clofazimine was started. This initially gave a marked improvement, but there was retraction of the lateral part of the lower lid and in November 1989 the patient complained of diplopia. Examination revealed underaction of the inferior oblique muscle, as illustrated by the Hess chart (Fig. 2), and it was thought that the disease had extended back to involve this muscle.

The condition had been very painful throughout, but in May 1990 the pain became extreme and the patient required admission for pain control. Narcotic analgesics were required to reduce the pain to a tolerable level. The right anterior chamber was seen for the first time to be shallow in comparison with the left, a moderate cataract was noted, and the globe appeared tethered, markedly restricting eye movements (Fig. 3).

A CT scan was carried out and this showed abnormal soft tissue shadowing lateral to the right globe extending back into the orbit lateral to and below the optic nerve. The abnormality extended close to the apex of the orbit but not intracranially (Fig. 4).

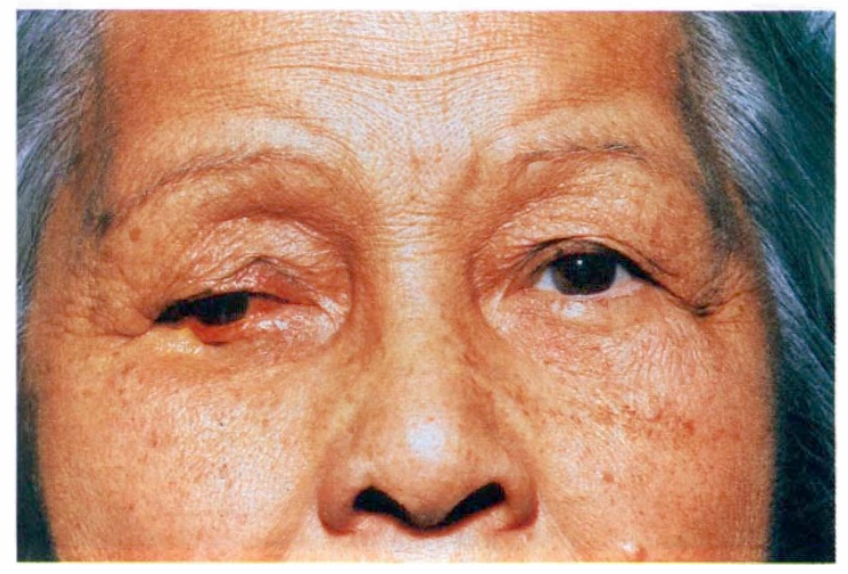

Fig. 6. Photograph, March 1991. 

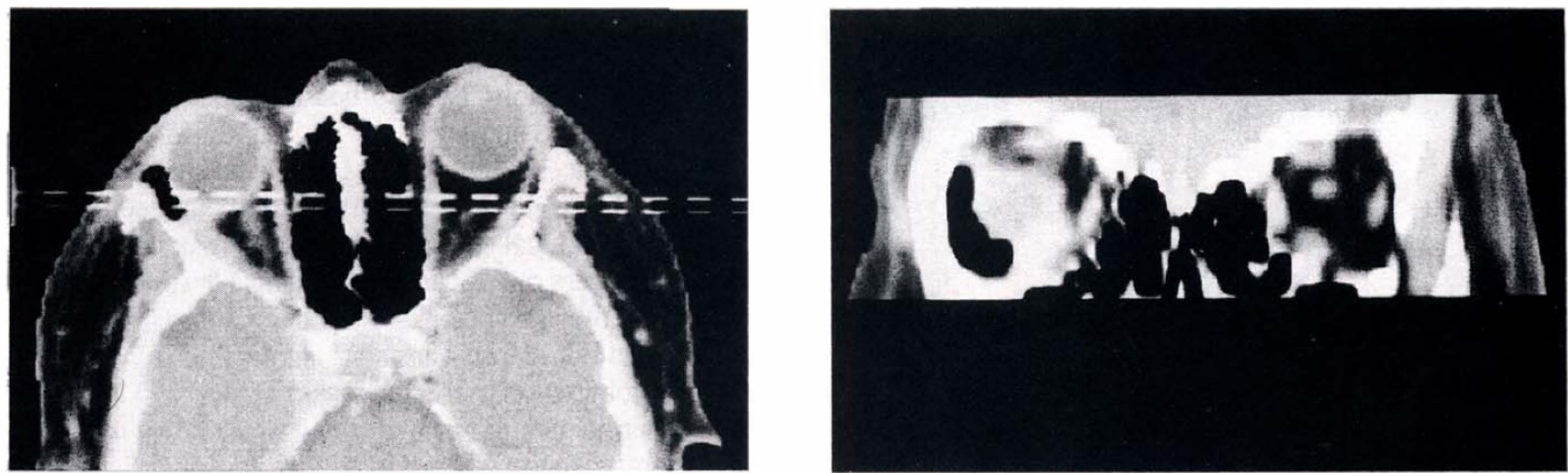

Fig. 7. CT scan and coronal reformat, April 1991. (NB: The right side of the patient is on the left side of the scans.)

In November 1990 the clofazimine was stopped because the patient developed icthyotic skin. Treatment was continued with prednisolone and minocycline.

In March 1991 the pain in the right orbit worsened and the abdominal lesion once again broke down. The patient was again admitted to hospital and the pain made tolerable but not abolished by administration of diamorphine and diclofenac.

The lateral canthal structures and conjunctival fornix had necrosed leaving. an opening plugged with a mucopurulent discharge. When this was cleaned out a deep cavity was revealed which extended back into the orbit behind the globe. The volume of the cavity was $4-5 \mathrm{ml}$ and the whole of the lateral side of the sclera was visible within it (Fig. 5). The eye was fixed in an abducted and depressed position (Fig. 6), and any remaining vision (6-60) was useless because of the fixed deviation. A further CT scan was done (Fig. 7) which showed the extent of the cavity.

The combination of prednisolone and cyclosporin A produced an improvement in the abdominal ulcer but no real change in the orbital necrosis. By May 1991 the lateral end of the lower lid had necrosed completely except for a marginal remnant and a corneal exposure ulcer had developed exacerbating the patient's pain. In mid July 1991 the cyclosporin A was discontinued due to side effects.

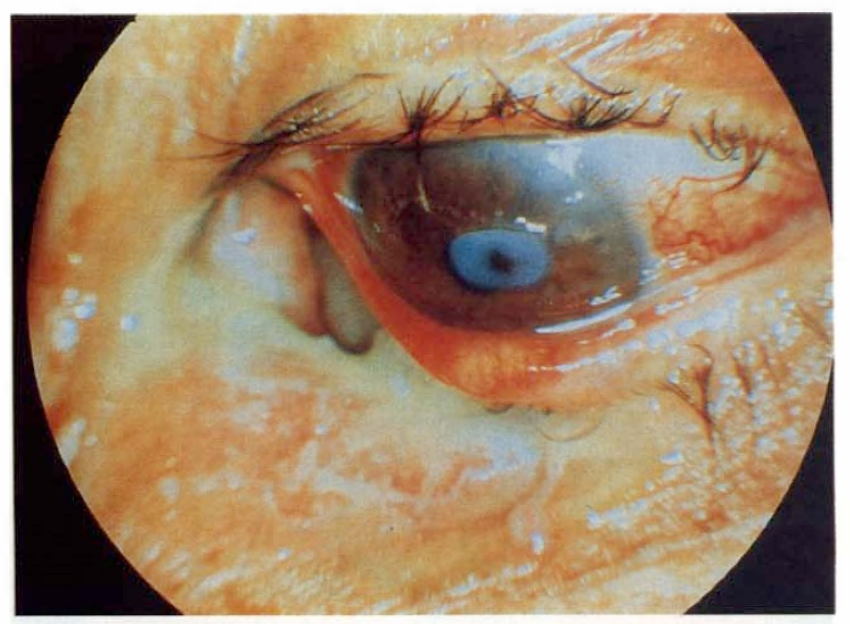

Fig. 8. Photograph, 26 July 1991.
Perforation of the right cornea, at the site of the exposure ulcer, occurred on 25 July 1991 (Fig. 8). It was. decided to embark upon a course of four treatments of hyperbaric oxygen therapy over 3 days prior to removal of the eye. On 26 July the patient had her first treatment. This consisted of three 30-minute periods of breathing 100\% oxygen at a pressure of 2 atmospheres interspaced with 10 -minute periods of breathing air.

The following day the patient was in intractable pain requiring narcotics and sedation, and surgery could be delayed no longer. Evisceration of the eye was chosen rather than enucleation in order that the meninges should not be opened.

At operation the cavity was found to extend from just above the lateral rectus muscle round to several millimetres medial to the inferior rectus muscle and back to a level just behind the posterior pole. Exposed bone of the inferior orbital plate and the lateral orbital wall formed the floor and lateral wall of the cavity. The globe was strongly fixed inferiorly, posteriorly and laterally and enucleation would have been impossible. Even after evisceration it was difficult to trim back the posterior and inferior sclera because it was fibrotic and adherent to the walls of the necrotic cavity. At the end of the procedure the optic nerve was left with a frill of 5-7 mm of sclera around it (Fig. 9).

Ten treatments of hyperbaric oxygen were given post-

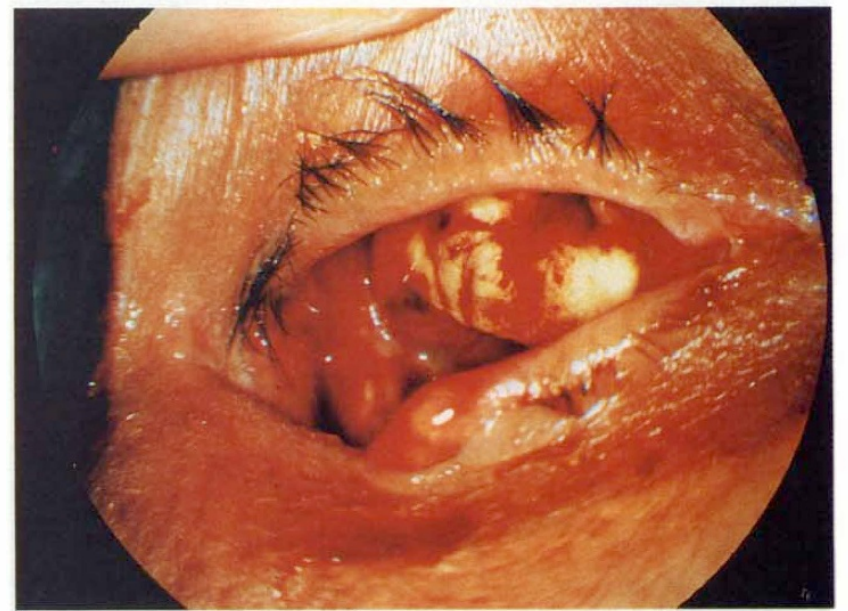

Fig. 9. Photograph, July 1991 


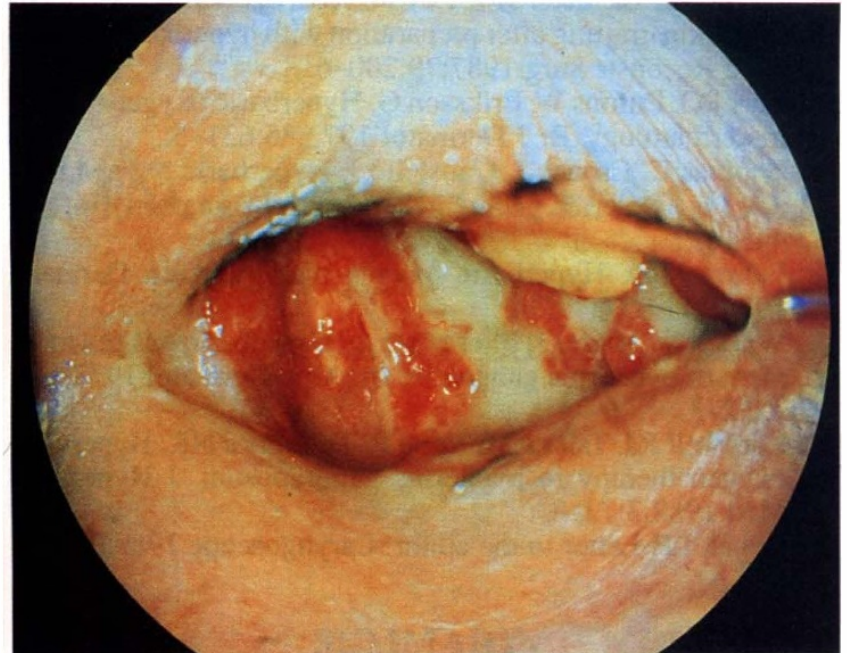

Fig. 10. Photograph. December 1991.

operatively and the cavity became lined with healthy granulations. Treatment was continued with prednisolone and clofazimine. However, on the tenth post-operative day the patient developed a pulmonary embolus which required anticoagulation.

The abdominal ulceration healed rapidly after the hyperbaric oxygen treatment. Over the 12 months since the evisceration the orbital wound has continued to granulate and although there was a superficial exudate this did not appear to impair the healing process (Fig. 10). The clofazimine has been stopped and the prednisolone is being slowly reduced. The abdominal ulcer remains healed.

\section{DISCUSSION}

There have been five reported cases of pyoderma gangrenosum with ophthalmic involvement. One case of upper lid involvement was resolved with dressings of chlorhexidine gluconate over a 2-month period." In another case bilateral corneal perforations were reported in 1983: however, no further information concerning this case is available. ${ }^{10}$ There have been two reported cases of scleritis. one of which responded to oral corticosteroids after 1 month" and the other which responded to a combination of cryotherapy, prednisolone and azathioprine.'? The most destructive case reported in the literature resulted in the loss of a patient's eye, and only after this when the patient was treated with clofazimine did the disease process abate. $^{13}$

Many modalities of treatment have been tried in pyoderma gangrenosum. ${ }^{1.2}$ It is usual to commence with external dressings, especially for small lesions. stepping up to intensive intralesional triamcinolone injections, which, when given early, achieve good results. The mainstay of treatment thereafter is corticosteroids. which cause an increase in chemotaxis, effective phagocytosis and intracellular killing by neutrophils. The steroid is usually given in the form of oral prednisolone although treatment with pulsed methylprednisolone ${ }^{6}$ in the form of $1 \mathrm{~g}$ daily for 5 days intravenously has been shown to be successful in some patients with resistant disease.
The activity of pyoderma gangrenosum often parallels that of any associated disease such as ulcerative colitis. It is therefore important to investigate and remedy any such disorder.

In recalcitrant disease or where steroid sparing is required other drugs have been tried with varying success. These treatments include the antibiotic minocycline, which probably acts through its immunosuppressive actions. Clofazimine, ${ }^{1:}$ which has similar effects to the corticosteroids on neutrophil function, is a useful drug but its use is limited by its side effects, which include icthyosis and infiltration of the small bowel lymphoid tissue. The immunosuppressive drugs azathioprine, chlorambucil and cyclosporin $A$ have all been reported to be effective with certain patients." 14

In the past, skin grafting was considered futile because such treatment could actually exacerbate the disease process and most grafts were rejected at 7-13 days. However. Davis et al. reported success in skin grafting 4 patients. 2 of whom had had multiple failed grafts in the past, the patients being treated pre- and post-operatively with hyperbaric oxygen therapy. ${ }^{15}$ There have also been reports of hyperbaric oxygen alone being used to treat this condition. ${ }^{16}$ " It appears that this treatment helps to reverse the impaired neutrophil function and promotes collagen production by the fibroblasts. Capillary angiogenesis is thought to result from the release of factors from hypoxic macrophages in the periods between treatments. ${ }^{21}$

In conclusion pyoderma gangrenosum is an unusual condition which is difficult to treat. In this case hyperbaric oxygen was used in the hope that it would prevent any exacerbation of the disease process caused by surgery. This it did and there has also been complete resolution of the abdominal ulcer and slow granulation of orbital site.

We would like to thank Dr. P Goodwin. Consultant Dermatologist, for his help with the general management and systemic drug treatment of this patient.

Key words: Hyperbaric oxygen. Orbit. Pyoderma gangrenosum.

\section{REFERENCES}

1. Schwaegeric SM. Bergleld WF. Senitzer D. Tidrick RT. Pyoderma gangrenosum: a review. J Am Acad Dermatol 1988:18:559-68.

2. Powell FC. Schroeter AL, Su WPD, Perry HO. Pyoderma gangrenosum: a review of 86 patients. Q J Med 1985:55 $173-86$

3. Callen JP. Pyoderma gangrenosum and related disorders. Adv Dermatol 1989:4:51-70).

4. Yco MS, Warnock GR, Cruickshank JC, Burnett JR. Pyoderma gangrenosum involving the head and neck. Laryngoscope 1988:98:765-8.

5. Wernik off S. Merritt C. Briggaman RA, Woodley DT. Malignant pyoderma or pyoderma gangrenosum of the head and neck? Arch Dermatol 1987:123:371-5.

6. Prystowsky JH. Kahn SN. Lazarus GS. Present status of pyoderma gangrenosum. Arch Dermatol 1989:125:57-64.

7. Brusting LA. Goeckerman WH, O'Leary PA. Pyoderma gangrenosum: clinical and experimental observations in five cases occurring in adults. Arch Dermatol 1930;22:655-80.

8. Lazarus GS. Goldsmith LA. Rocklin RE, et al. Pyoderma gangrenosum, altered delayed hypersensitivity, and polyarthritis. Arch Dermatol 1972:105:46-51 
9. Magid ML, Gold MH. Treatment of recalcitrant pyoderma gangrenosum with cyclosporine. J Am Acad Dermatol 1989;20:293-4.

10. Browning DJ, Proia AD, Sanfilippo FP. Pyoderma gangrenosum involving the eyelid. Arch Ophthalmol 1985;103: $551-2$.

11. Goettmann S, Guillaume JC, Binaghi M, et al. Pyoderma gangrenosum superficiel avec histologie pseudo-tuberculoide et atteinte oculaire. Ann Dermatol Venerol 1989;116: 831-2.

12. Happle R, Schiffer H-P, Kovary PM. Ocular involvement in pyoderma gangrenosum. Arch Dermatol 1977;113:1612.

13. Mensing $\mathrm{H}$. Clofazimine in dermatitis ulcerosa (pyoderma gangrenosum). Dermatologica 1988;177:232-6.

14. Callen JP, Case JD, Sager D. Chlorambucil: an effective corticosteroid-sparing therapy for pyoderma gangrenosum. J Am Acad Dermatol 1989;21:515-9.
15. Davis JC, Landeen JM, Levine RA. Pyoderma gangrenosum: skin grafting after preparation with hyperbaric oxygen. Plast Reconstr Surg 1987;79:200-6.

16. Barr PO, Enfons W, Eriksson G. Hyperbaric oxygen therapy in dermatology. Br J Dermatol 1972;86:631-5.

17. Thomas C, Crouch J, Gaustello J. Hyperbaric oxygen therapy for pyoderma gangrenosum. Arch Dermatol 1974;110: 445-6.

18. Fuhrman D. Hyperbaric oxygen therapy. Arch Dermatol 1975;111:657.

19. Wyrick W, Mader J, Eller M, et al. Hyperbaric oxygen treatment of pyoderma gangrenosum. Arch Dermatol 1978;114: 1232-3.

20. Cardwell RJ, Taha AM, Vonu P, Thomford NR. Hyperbaric oxygen therapy in pyoderma gangrenosum. J Hyperbaric Med 1988;3:73-8.

21. Rybak LP. Letter to the editor. Laryngoscope 1989;99:112. 